\title{
Why are multi-centre clinical observational studies still so difficult to run?
}

\author{
J. Sandy, ${ }_{1}$ N. Kilpatrick, ${ }^{2}$ M. Persson, ${ }^{3}$ A. Bessel, ${ }_{1}^{4}$ A. Waylen, ${ }^{5}$ A. Ness ${ }^{6}$ \\ and $\mathrm{A}$. Ireland ${ }^{7}$
}
IN BRIEF
- Provides information on the approvals process for obtaining permissions for running multicentre observational studies.
- Outlines the difficulties that might be encountered in obtaining these approvals.
- Makes suggestions to streamline the approvals process.

Despite the introduction of IRAS, obtaining REtD approvals for multicentre studies is a major rate limiting step. Our experience with cleft research demonstrates that this approvals process must be drastically and rapidly improved if we wish to continue attract clinical research to the UK.

\section{INTRODUCTION}

The introduction of IRAS (Integrated Research Application System) has streamlined the approvals processes for research studies in the UK. However, a major rate limiting step still exists in the form of R\&D approvals for multicentre studies. Our experiences with RetD in gaining the necessary approvals for a multicentre observational study examining cleft lip and palate services in the UK highlight the principal difficulties. Recommendations are made as to how the process could be radically improved.

\section{CLINICAL RESEARCH IN THE NHS}

The UK has the potential to be a world leader in clinical research because it has a relatively large population living in a small geographical area, covered by a single comprehensive healthcare system - the National Health Service (NHS). In recent years there has been a realisation that to attract large funded multicentre clinical studies to the UK, the process for gaining research approvals must be streamlined.

\footnotetext{
${ }^{*}$ Head of School and Professor of Orthodontics, ${ }^{2}$ Professor of Paediatric Dentistry, ${ }^{3}$ Project Manager/ Research Fellow, ${ }^{4}$ Systematic Reviewer, ${ }^{5}$ Lecturer in Psychology, ${ }^{6}$ Professor of Epidemiology, ${ }^{7}$ Reader in Orthodontics, School of Oral \& Dental Sciences, University of Bristol, Lower Maudlin Street, Bristol BS1 2LY ${ }^{*}$ Correspondence to: Professor Jonathan Sandy Email: jonathan.sandy@bristol.ac.uk
}

\section{Refereed Paper}

Accepted 13 May 2011

DOI: $10.1038 /$ sj.bdj.2011.570

${ }^{\circ}$ British Dental Journal 2011; 211: 59-61
The advantages of such studies to the UK include direct financial investment, job creation, infrastructure development and within the NHS, a proportion of patient treatment costs. The UK Government are fully aware of the benefits and have not only reallocated resources, but have developed several initiatives to improve the process of approving and funding clinical research. Two important initiatives have been the introduction of IRAS and the NIHR portfolio.

IRAS comprises a coordinated system for gaining NHS Permissions (NIHR CSP) where applications for Ethics and Research and Development (R\&D) can be made along with other approvals, such as MHRA (Medical and Healthcare products Regulatory Agency), using just one online application system. This is a major advance over the previous system, not only for single but also multicentre studies where Site Specific Information (SSI) is automatically generated online. Partly as a result of introducing this system applying for ethical approval has become easier.

The NIHR portfolio has been introduced to provide service support costs and also the research governance costs associated with research. Once on the portfolio, researchers can access RetD infrastructure and support, research governance, training courses such as Good Clinical Practice (GCP), research nurses, administrators and additional costs incurred by the study eg nursing, pharmacy, imaging and clinician's time. Adoption onto the portfolio is automatic for those studies funded by the
NIHR, such as RfPB (Research for Patient Benefit) and HTA (Health Technology Assessment), along with those funded by the NIHR's non-commercial partners eg the Wellcome Trust and UK Medical Research Council. ${ }^{1}$ This has not only ensured that NHS funding for research follows funded and approved activity, but has encouraged both primary and secondary care trusts to participate in research.

Given these changes the process of setting up a study and gaining necessary approvals should now be straightforward. However, gaining R\&D approvals at multiple sites has become more challenging and is now the main rate limiting step in setting up clinical research studies in the UK.

\section{ARE THE NEW SYSTEMS WORKING?}

Recent correspondence in the broadsheets has suggested that if the NHS wishes to engage in world-class research, R\&D departments in hospital and primary care trusts need a radical overhaul. ${ }^{2}$ This was echoed by Fudge et $a .^{3}$ in their Stroke Survivor Needs Survey in 44 practices across the UK, where approvals took between seven and 135 days, and in the IMPROVE trial where permissions took up to 50 weeks. ${ }^{4}$ The point was made in subsequent correspondence that the autonomy being promoted by Government policy, which encouraged individual NHS organisations (and their R\&D departments) to work independently in order to meet their local needs, was partly to blame. ${ }^{5}$ More recently, the Academy of Medical Sciences 
have reviewed the permissions process and have acknowledged inconsistencies of approach in granting approvals across R\&D departments. ${ }^{6}$ Particular problems were identified for multicentre studies regarding duplication of permissions and differing interpretations of checks and requirements by each R\&D department.

\section{OUR EXPERIENCE OF RUNNING A MULTICENTRE OBSERVATIONAL STUDY}

In 2008 we were awarded an NIHR Programme Grant to examine head and neck cancer and cleft lip and palate services in the UK. We are well placed to conduct this study having carried out a similar project under the auspices of the Clinical Standards Advisory Group (CSAG) in 1998. ${ }^{7}$ The original CSAG study required no ethical approval (being regarded as audit), collected outcome and service evaluation data across 57 sites and was completed in 18 months. As a result, cleft services in the UK were centralised to 18 sites. The focus of the 2008 programme grant is an evaluation of the impact of this centralisation process. Once again we are collecting patient outcome and process data.

Such a project should be less challenging than running a clinical trial as we are collecting observational (mainly clinical) data rather than carrying out an intervention. Following centralisation there should be fewer clinicians and clinical services to interact with than previously (only 18 sites). However, this has not been the case and we have only recently started to collect outcome data. The R\&D process has been the major rate limiting step. We have found repeated inconsistencies in the interpretation of rules by staff, who although willing and helpful, are often unsure of the regulations. This has been exacerbated by a high turnover of R\&D staff in some instances.

Using the new IRAS system, in 2008 we applied for and gained ethical and global RED approval online. This took 154 days. We then set about acquiring RetD approval from each of the individual trial sites. To date we are still awaiting three local R\&D approvals and this is some 327 days since the initial ethics submission.

In order to minimise the burden for local PIs, usually busy clinicians, the Bristol research team completed the SSI

\begin{tabular}{|c|c|c|c|c|c|c|c|}
\hline Centre & $\begin{array}{l}\text { Letter of } \\
\text { access }\end{array}$ & $\begin{array}{l}\text { Research } \\
\text { passport }\end{array}$ & $\begin{array}{l}\text { Honorary } \\
\text { contract }\end{array}$ & $\begin{array}{l}\text { Enhanced } \\
\text { CRB }\end{array}$ & $\begin{array}{l}\text { Occupational } \\
\text { health }\end{array}$ & $\mathrm{GCP}$ & $\begin{array}{l}\text { CV in RCtD } \\
\text { format }\end{array}$ \\
\hline 1 & Yes & Yes & No & Yes & $\begin{array}{l}\text { Proof of hepatitis } \\
\text { vaccination }\end{array}$ & Yes & Yes \\
\hline 2 & Yes & Yes & No & Yes & Researchers Trust & Yes & Yes \\
\hline 3 & Yes & Yes & No & Yes & Yes/Maybe & Yes & Yes \\
\hline 4 & Maybe & Maybe & Maybe & No & Maybe & Yes & Yes \\
\hline 5 & Yes & Yes & No & No & No & Yes & Yes \\
\hline 6 & No & No & Yes & No & Yes & Yes & Yes \\
\hline 7 & No & No & Yes & Yes & Maybe & Yes & Yes \\
\hline 8 & No & No & Yes & Yes & Maybe & Yes & Yes \\
\hline 9 & No & No & Yes & Yes & No & Yes & Yes \\
\hline 10 & No & No & Yes & No & Yes & Yes & Yes \\
\hline 11 & No & No & Yes & No & Maybe & Yes & Yes \\
\hline 12 & No & No & Yes & No & Maybe & Yes & Yes \\
\hline 13 & No & No & Yes & Yes & Maybe & Yes & Yes \\
\hline 14 & Yes & Yes & No & No & No & Yes & Yes \\
\hline 15 & No & No & Yes & Yes & Maybe & Yes & Yes \\
\hline 16 & No & No & Yes & No & Maybe & Yes & Yes \\
\hline 17 & No & No & Yes & No & Maybe & Yes & Yes \\
\hline 18 & No & No & Yes & No & Maybe & Yes & Yes \\
\hline
\end{tabular}

section of the IRAS form for each centre. A number of issues arose with this process. Initially R\&D departments insisted that every member of each local multidisciplinary clinical team was expected to provide a CV and have their details entered on their SSI form. However, we negotiated with individual R\&D departments that they would request only the CVs of the clinical leads within each team (eg paediatric dentist, cleft surgeon, speech and language therapist). This still totalled eight CVs per team, so that including the Bristol research team, $140 \mathrm{CVs}$ were required.

Secondly, requirements for completion of the SSI forms varied between REtD departments. Some required simple sign off by the Head of Department(s), others requested internal financial approval and others appeared to step outside their remit, requesting changes to patient/parent information sheets that had already been approved centrally by Ethics. Such variations often took weeks to process and sometimes required approval from large committees (who met infrequently) to finalise completion.
Once local SSI forms were completed, contracts were issued between the sponsoring organisation (trust) and the 18 local sites. Each contract required close communication between sponsoring R\&D and local R\&D departments, a process requiring support from the Bristol research team. Despite constant input and facilitation we are still waiting for contractual sign off at three sites.

An additional layer of complexity arose as up to four members of the Bristol based research team were required to attend clinics at the 18 centres to ensure standardisation of methodology and measurements, to allow valid comparisons between centres. Before this, letters of access (LOA), research passports (RP) and/or honorary contracts (HC) had to be issued. The Bristol team includes two NHS employed researchers, one university-employed researcher with an honorary NHS contract and one university-employed researcher with no honorary contract. Requirements for access differed for each researcher across study sites regarding the necessity of LOAs, RPs, honorary contracts, occupational health 
clearance and Criminal Record Bureau (CRB) checks (Table 1). Trusts that did not require an LOA or RP did require honorary contracts. Having issued honorary contracts one trust then requested that the research team attend an Induction and Orientation course. Given that the total amount of time we planned to spend in this trust was no more than three days in an 18 month period, this seemed disproportionate. Even the forms used to generate the LOA varied. We started by using the standard proforma (available through the NIHR website ${ }^{8}$ ) for all sites, but two sites asked us to use their bespoke application forms leading to further delays. Although the study subjects were all children not all sites requested an Enhanced CRB check. Occupational health requirements were equally inconsistent. It was hoped the host R\&D and/or human resources departments would have supported their local teams, but they appear to have been swamped by the administrative processes this system has created. On many occasions the research team had to clarify matters for R\&D departments who were unsure of the regulation detail.

The time required to complete the REtD approvals process and to gain access to local sites for data collection has been excessive. Currently, there are still unresolved issues and we have not yet started data collection at all sites. Consequently pre-arranged data collection visits have been postponed, wasting researcher, clinician and ultimately patient/families' time.

\section{SUMMARY AND RECOMMENDATIONS}

On a positive note, there is now direction from the Academy of Medical Sciences that the public and researchers have a common interest in ensuring that research is conducted safely and effectively and that regulation should be proportionate to the risks and benefits. The report ${ }^{6}$ mapped out existing constraints as: delays and duplication in obtaining research permissions from NHS Trusts, complexity and inconsistency across the regulation pathway, a lack of proportionality in the regulation of clinical studies and inappropriate constraints on access to health data. This is recognised as hampering clinical studies and discouraging academic and commercial health research sponsors from conducting studies in the UK. The report makes a number of recommendations and it states: 'Obtaining NHS permissions was identified as the single greatest barrier to health research and the rate-limiting step in most studies. Changes are needed to reduce bureaucracy and increase the speed of NHS RED permissions by replacing multiple, inconsistent, slow checks by individual NHS Trusts, with a single, consistent, efficient process for the NHS as a whole.'

The system of RED approvals has to change if we are to attract clinical research to the UK. Undoubtedly the system can be made to work efficiently and effectively if commonsense prevails and permissions for multicentre studies are processed centrally using the current IRAS online system. Failure to address these problems urgently may see a decline in clinical research in the UK and without this, patient care, outcomes and quality of life cannot improve, irrespective of how much governance and paperwork is in place.

For clinical observational studies like ours there are some additional issues. Delays in recruitment to trials may waste time and resources but they are unlikely to affect the validity of the trial. Also randomisation may well iron out any subtle differences with eligibility criteria or measurement between centres. For observational studies this is not the case. Delays mean that comparisons may no longer be valid and systematic differences in measurement between centres could create artefactual differences in outcome. Furthermore the findings of trials are not likely to be affected by the percentage of eligible participants recruited, whereas those for observational studies may well be a function of the response rate if linked to outcome. For these reasons it is crucial that
REtD approvals are not only speeded up but also synchronised. It is also important the support cost mechanism is reviewed, so that (where appropriate) some support costs can be directly allocated to central research teams and that rewards take account of response rate as well as numbers recruited.

Within the RED approvals process we would like to see:

- A single RAD process for multicentre studies

- Timelines to progress all RetD approvals to be agreed and coordinated centrally

- CRB checks should be held centrally or by the single sponsoring trust

- A single universally accepted file or passport (CVs, SSIs etc) for researchers accessing multiple sites.

We await the outcome of the forthcoming NIHR CSP report on this subject.

This publication presents independent research commissioned by the National Institute for Health Research (NIHR) under its Programme Grants for Applied Research scheme (RP-PG-0707-10034). The views expressed in this publication are those of the author(s) and not necessarily those of the NHS, the NIHR or the Department of Health.

1. Department of Health. Eligibility for inclusion of studies in the NIHR Clinical Research Network Portfolio, Version 3. London: Department of Health, January 2008. http://www.crncc.nihr.ac.uk/ about_us/processes/portfolio/p_eligibility (accessed 7 February 2011).

2. Jack A. Making a virtue of patients. Financial Times 2010 March 15. http://www.ft.com/ $\mathrm{cms} / \mathrm{s} / 0 / 44 b 0 f 7 a c-305 f-11 \mathrm{df}-\mathrm{bc} 4 a-0144 f e a b d c 0$. html\#axzz1E9oet0HA.

3. Fudge N, Redfern J, Wolfe C, McKevitt C Streamlined research governance: are we there yet? BMJ 2010; 341: doi:10.1136/bmj.c4625 (published 27 August 2010)

4. The IMPROVE Trial Management Committee. Getting research in the NHS started. Lancet 2010; 375: 2072.

5. Sitzia J, Messer J. Streamlining research governance. [Online correspondence]. BMJ 2010; http:// www.bmj.com/content/341/bmj.c4625/reply (published 20 October 2010)

6. Academy of Medical Sciences. A new pathway for the regulation and governance of health research London: The Academy of Medical Sciences, 2011.

7. Sandy J R, Williams AC, Bearn D et al. Cleft lip and palate care in the United Kingdom - the Clinical Standards Advisory Group (CSAG) Study. Part 1: background and methodology. Cleft Palate Craniofac J 2001: 38: 20-23.

8. National Institute of Health Research. Research in the NHS - Human Resources (HR) Good Practice Resource Pack. http://www.nihr.ac.uk/systems/ Pages/systems_research_passports.aspx (accessed 4 July 2011). 